Article

\title{
Isolation and Identification of Potent Antidiabetic Compounds from Antrodia cinnamomea-An Edible Taiwanese Mushroom
}

\author{
Hung Tse Huang ${ }^{1,2}$, San-Lang Wang ${ }^{3,4, * \mathbb{D}}$, Van Bon Nguyen ${ }^{5, * \mathbb{D}}$ and Yao-Haur Kuo ${ }^{2,6,7, *}$ \\ 1 Department of Biochemical Science and Technology, National Taiwan University, Taipei 106, Taiwan; \\ kk49310953@nricm.edu.tw \\ 2 Division of Chinese Materia Medica Development, National Research Institute of Chinese Medicine, \\ Taipei 11221, Taiwan \\ 3 Department of Chemistry, Tamkang University, New Taipei City 25137, Taiwan \\ 4 Life Science Development Center, Tamkang University, New Taipei City 25137, Taiwan \\ 5 Institute of Research and Development, Duy Tan University, Da Nang 550000, Vietnam \\ 6 Graduate Institute of Integrated Medicine, College of Chinese Medicine, China Medical University, \\ Taichung 40402, Taiwan \\ 7 Ph.D. Program for Clinical Drug Development of Chinese Herbal Medicine, College of Pharmacy, Taipei \\ Medical University, Taipei 11031, Taiwan \\ * Correspondence: sabulo@mail.tku.edu.tw (S.-L.W.); bondhtn@gmail.com (V.B.N.); \\ kuoyh@nricm.edu.tw (Y.-H.K.); Tel.: +886-2-2621-5656 (S.-L.W.); Fax: +886-2-2620-9924 (S.-L.W.)
}

Received: 16 September 2018; Accepted: 1 November 2018; Published: 2 November 2018

check for updates

\begin{abstract}
Antrodia cinnamomea (AC), an edible Taiwanese mushroom, has been recognized as a valuable natural resource with vast biological and medicinal benefits. Recently, the hypoglycemic and anti-diabetic effects of AC were mentioned in several studies. However, no studies have investigated $\alpha$-glucosidase inhibitors from AC fruiting bodies (ACFB) as they relate to type 2 diabetes (T2D) treatment. The purpose of this study was to gain evidence of potent $\alpha$-glucosidase inhibitory effects, as well as isolate, identify and characterize the active compounds of ACFB. The MeOH extract of ACFB demonstrated potent $\alpha$-glucosidase inhibitory activity, and possessed high $\mathrm{pH}$ stability ( $\mathrm{pH} 2-11$ ) and thermostable properties at $40-50{ }^{\circ} \mathrm{C}$. Further purification led to the isolation of eight constituents from ACFB, identified as: 25S-antcin K (1), 25R-antcin K (2), dehydrosulphurenic acid (3), 25S-antcin I (4), 25S-antcin B (5), 25R-antcin B (6), dehydroeburicoic acid (7) and eburicoic acid (8). Notably, the ACFB extract and its identified compounds, except 1, 4, and 6 demonstrated a greater effect $\left(\mathrm{EC}_{50}=0.025-0.21 \mathrm{mg} / \mathrm{mL}\right)$ than acarbose $\left(\mathrm{EC}_{50}=0.278 \mathrm{mg} / \mathrm{mL}\right)$. As such, these active compounds were determined to be new potent mushroom $\alpha$-glucosidase inhibitors. These active compounds were also identified on the HPLC fingerprints of ACFB.
\end{abstract}

Keywords: Antrodia cinnamomea; antidiabetic; edible mushroom; $\alpha$-glucosidase inhibitor; antcin K; dehydrosulphurenic acid; dehydroeburicoic acid; eburicoic acid

\section{Introduction}

The incidence of diabetes mellitus (DM), a chronic metabolic disorder, has been dramatically increasing and reducing people's quality of life worldwide [1]. People with DM are at high risk for many other complications, including kidney failure, depression, cardiovascular disease, frailty, cognitive decline or premature death [2]. The number of diabetics was reported to be 382 million. Of these, $90 \%$ of cases in 2013 were type 2 diabetes (T2D), and the number of total DM cases is estimated to increase to 592 million by 2035 [3]. T2D has been managed by several therapies, including 
the use of $\alpha$-glucosidase inhibitors (aGIs) [4]. Currently, several commercial aGIs, such as acarbose, voglibose and miglitol, are available however some side effects have been reported, including diarrhea, flatulence and abdominal discomfort [5]. Therefore, the search for safe and natural sources of active aGIs, along with their isolation and identification, is a high priority.

aGIs may be obtained from several common natural sources, including medicinal herbs, microbial conversion, edible and medicinal mushrooms [5-20]. Of these, numerous herbal sources show an $\alpha$-glucosidase inhibitory effect, and their isolated aGI compounds have already been reported [5-10]. Similarly, numerous aGI compounds from the culture broth of microbes were recently investigated [1,11-15], and several edible and medicinal mushroom species have been investigated for their enzyme inhibitory effect related to T2D [16-19].

Edible and medicinal mushrooms were reported to be commonly used as folk medicine in Asian countries to manage various diseases [20-22]. Of these, Antrodia cinnamomea (AC), an edible Taiwanese mushroom, was recognized early on for its valuable use in Chinese folk medicine to treat diarrhea, hypertension, allergies, abdominal pain, food and drug intoxication, skin itching and tumorigenic diseases [23]. Research shows that AC possesses vast biological activities, including anti-NO, anti-oxidative, anti-metastatic, hepato-protective, anti-hyperlipidemic, immunomodulatory, cardio-protective, neuro-protective, and anticancer activities [24-26]. AC also demonstrated a reducing effect on total cholesterol, plasma triglycerides and low-density lipoprotein levels in obese hamsters [27]. Recently, several isolated compounds from AC, including dehydroeburicoic acid [28], ergostatrien-3 $\beta$-ol [29], antcin K [30] and eburicoic acid [31], showed a hyperglycemic effect and antidiabetic properties via the glucose transporter 4 (GLUT4) and palmitate-treated C2C12 myotubes in mice fed a high-fat diet [31]. Hwang et al. (2015) reported $\alpha$-glucosidase inhibitory activity in the extracts of A. cinnamomea mycelia and concentrated culture filtrate [32]. However, according to our literature review, no studies reported on using $\alpha$-glucosidase inhibitors from $A$. cinnamomea fruiting bodies for T2D management until now. The object of this study was to establish A. cinnamomea as a potent natural source of $\alpha$-glucosidase inhibitor constituents that could be useful in T2D treatment.

To achieve this goal, A. cinnamomea fruiting bodies (ACFB) were extracted by methanol, then evaluated for its $\alpha$-glucosidase inhibitory activity and stability property. The major active fractions of ACFB were purified for isolation of active compounds by coupling with an $\alpha$-glucosidase inhibitory assay. Inhibition modes of the inhibitors and the retention times (RT) of these active compounds on the HPLC fingerprint of the ACFB extract were also determined. The results of this study contributed to the catalogue of novel biological activities of $\mathrm{AC}$, as well as its constituents.

\section{Results and Discussion}

\subsection{New Evidence of A. Cinnamomea as a Potent Natural Source of $\alpha$-Glucosidase Inhibitors}

ACFB were extracted by methanol and used for bioassay. As shown in Figure S1, ACFB demonstrated potent $\alpha$-glucosidase inhibitory activity with a high level of maximum inhibition at $99 \%$ (at $1.2 \mathrm{mg} / \mathrm{mL}$ ) and a low $\mathrm{EC}_{50}$ value of $0.205 \mathrm{mg} / \mathrm{mL}$. Acarbose, a commercial antidiabetic drug, was tested for comparison and showed a lower inhibitory effect (max inhibition $=90.6 \%$ at $2.5 \mathrm{mg} / \mathrm{mL}, \mathrm{EC}_{50}=0.278 \mathrm{mg} / \mathrm{mL}$ ) than that of ACFB.

Notably, the potent $\alpha$-glucosidase inhibitory activity of ACFB extract $\left(\mathrm{EC}_{50}=0.205 \mathrm{mg} / \mathrm{mL}\right)$ was a novel finding in this study, and showed higher activity than that of $A$. cinnamomea mycelia extract $\left(\mathrm{EC}_{50}=310 \mathrm{mg} / \mathrm{mL}\right), A$. cinnamomea cultural filtrate extract $\left(\mathrm{EC}_{50}=310 \mathrm{mg} / \mathrm{mL}\right)$ [32] or Trametes pubescens fruiting bodies extract $(\geq 1.0 \mathrm{mg} / \mathrm{mL})$ [17]. ACFB also demonstrated comparable or higher activity than other edible mushroom extracts $\left(\mathrm{EC}_{50}=0.0378-0.325 \mathrm{mg} / \mathrm{mL}\right)[18,19]$, culture broths of selected aGI-producing bacterial strains $\left(\mathrm{EC}_{50}=0.038-3.0 \mathrm{mg} / \mathrm{mL}\right)[1,11,13,14]$ and some recently reported herbal extracts $\left(\mathrm{EC}_{50}=0.17-1.42 \mathrm{mg} / \mathrm{mL}\right)[6-9]$. The comparison is briefly summarized in Table 1. 
Table 1. $\alpha$-glucosidase inhibition by recently reported natural source extracts.

\begin{tabular}{|c|c|c|c|c|}
\hline Scientific Name & & $\begin{array}{l}\text { Solvents for } \\
\text { Extraction }\end{array}$ & $\mathrm{EC}_{50}(\mathrm{mg} / \mathrm{mL})$ & Ref. \\
\hline Mushroom & Part Used & & & \\
\hline Acarbose (positive control) & - & & $0.278 \pm 0.0023$ & This \\
\hline A. cinnamomea & Fruiting body & $\mathrm{MeOH}$ & $0.205 \pm 0.0084$ & study \\
\hline A. cinnamomea & Mycelia & $80 \% \mathrm{MeOH}$ & 310 & [32] \\
\hline A. cinnamomea & Cultural filtrate & $80 \% \mathrm{MeOH}$ & 284 & [32] \\
\hline Pleurotus cornucopiae & Fruiting body & $\mathrm{H}_{2} \mathrm{O}$ & 23.2 & [16] \\
\hline Trametes pubescens & Fruiting body & $80 \% \mathrm{MeOH}$ & $\geq 1.0$ & [17] \\
\hline T. pubescens & Fruiting body & Hot $\mathrm{H}_{2} \mathrm{O}$ & $\geq 1.0$ & [17] \\
\hline Pleurotus eous & Fruiting body & $\mathrm{MeOH}$ & $\overline{0.325}$ & [18] \\
\hline P. eous & Fruiting body & $\mathrm{H}_{2} \mathrm{O}$ & 0.280 & [18] \\
\hline Grifola frondosa & Fruiting body & $n$-hexane & 0.0376 & [19] \\
\hline Hericium erinaceum & Fruiting body & $n$-hexane & 0.0389 & [19] \\
\hline Agaricus blazei & Fruiting body & $n$-hexane & 0.0528 & [19] \\
\hline Ganoderma lucidum & Fruiting body & $n$-hexane & 0.0766 & [19] \\
\hline Coriolus versicolor & Fruiting body & $n$-hexane & 0.125 & [19] \\
\hline Phellinus linteus & Fruiting body & n-hexane & 0.165 & [19] \\
\hline Bacteria & C/N Source & & & \\
\hline Paenibacillus sp. & Shrimp shells & \multirow{6}{*}{ Culture broths * } & 0.108 & [11] \\
\hline Paenibacillus sp. & Shrimp heads & & 0.455 & [11] \\
\hline Paenibacillus sp. & Crab shells & & 0.038 & [11] \\
\hline Paenibacillus sp. & Nutrient broths & & 0.081 & [14] \\
\hline Paenibacillus sp. & Squid pens & & 0.252 & [1] \\
\hline $\begin{array}{l}\text { Co-culture of Bacillus } \\
\text { mycoides and Rhizobium sp. }\end{array}$ & Shrimp heads & & 3.0 & {$[13]$} \\
\hline Medicinal Plants & Part Used & & & \\
\hline Dalbergia tonkinensis & Heartwood & $\mathrm{MeOH}$ & 0.17 & [9] \\
\hline D. tonkinensis & Bark & $\mathrm{MeOH}$ & 0.57 & [9] \\
\hline D.a tonkinensis & Leaves & $\mathrm{MeOH}$ & 0.78 & [9] \\
\hline Terminalia bellirica & Trunk bark & $\mathrm{MeOH}$ & 0.41 & [7] \\
\hline Terminalia corticosa & Trunk bark & $\mathrm{MeOH}$ & 1.42 & [7] \\
\hline Cinnamomum cassia J. S. Presl. & Trunk bark & $\mathrm{MeOH}$ & 1.08 & [6] \\
\hline Terminalia bellirica & Leaves & $\mathrm{MeOH}$ & 0.66 & [6] \\
\hline Psidium littorale Raddi & Leaves & $\mathrm{MeOH}$ & 0.25 & [8] \\
\hline
\end{tabular}

* were dehydrated to powder form, then dissolved in water before testing for $\alpha$-glucosidase inhibitory activity.

\subsection{Isolation and Identification of Active Constituents from A. cinnamomea}

The methanol extract of ACFB was fractionated and sub-fractionated; active compounds were isolated via silica gel flash column (70-230 mesh, $15 \times 10 \mathrm{~cm}, 0.9 \mathrm{~kg}$ ) and preparative HPLC (Cosmosil 5C18-AR-II, $5 \mu \mathrm{m}, 250 \times 20 \mathrm{~mm}$ i.d.). The purification process is briefly summarized in Figure 1 .

$\mathrm{ACFB}$ extract was primarily separated into 12 fractions via silica column. The four major fractions, ACFB-3, ACFB-5, ACFB-6 and ACFB-9, were eluted with the gradient solvent system of $\mathrm{CH}_{2} \mathrm{Cl}_{2} / \mathrm{MeOH}$ at a ratio of $17 / 83-24 / 76,33 / 67-42 / 58,43 / 57-52 / 48$ and $69 / 31-76-24$, respectively. These were then evaluated for aGIs before undergoing further purification. The results in Figure S1a,b in the supplementary section indicate that all four fractions demonstrated potent aGIs with max inhibition and $\mathrm{EC}_{50}$ values of $85 \%$ and $0.366 \mathrm{mg} / \mathrm{mL}, 98 \%$ and $0.04 \mathrm{mg} / \mathrm{mL}, 94 \%$ and $0.246 \mathrm{mg} / \mathrm{mL}$, and $99 \%$ and $0.084 \mathrm{mg} / \mathrm{mL}$, respectively. Of these, fractions ACFB- 5 and ACFB- 9 possessed the strongest activity due to their small $\mathrm{EC}_{50}$ values, ranked at $F$ level based on Duncan's multiple range test at $\alpha=0.01$. The other two fractions, ACFB-3 and ACFB-6, showed acceptable activity compared to the crude extract and positive control (acarbose). Further sub-separation and recycling via preparative HPLC resulted in eight compounds. 


\section{Dried sample of ACFB (200g)}

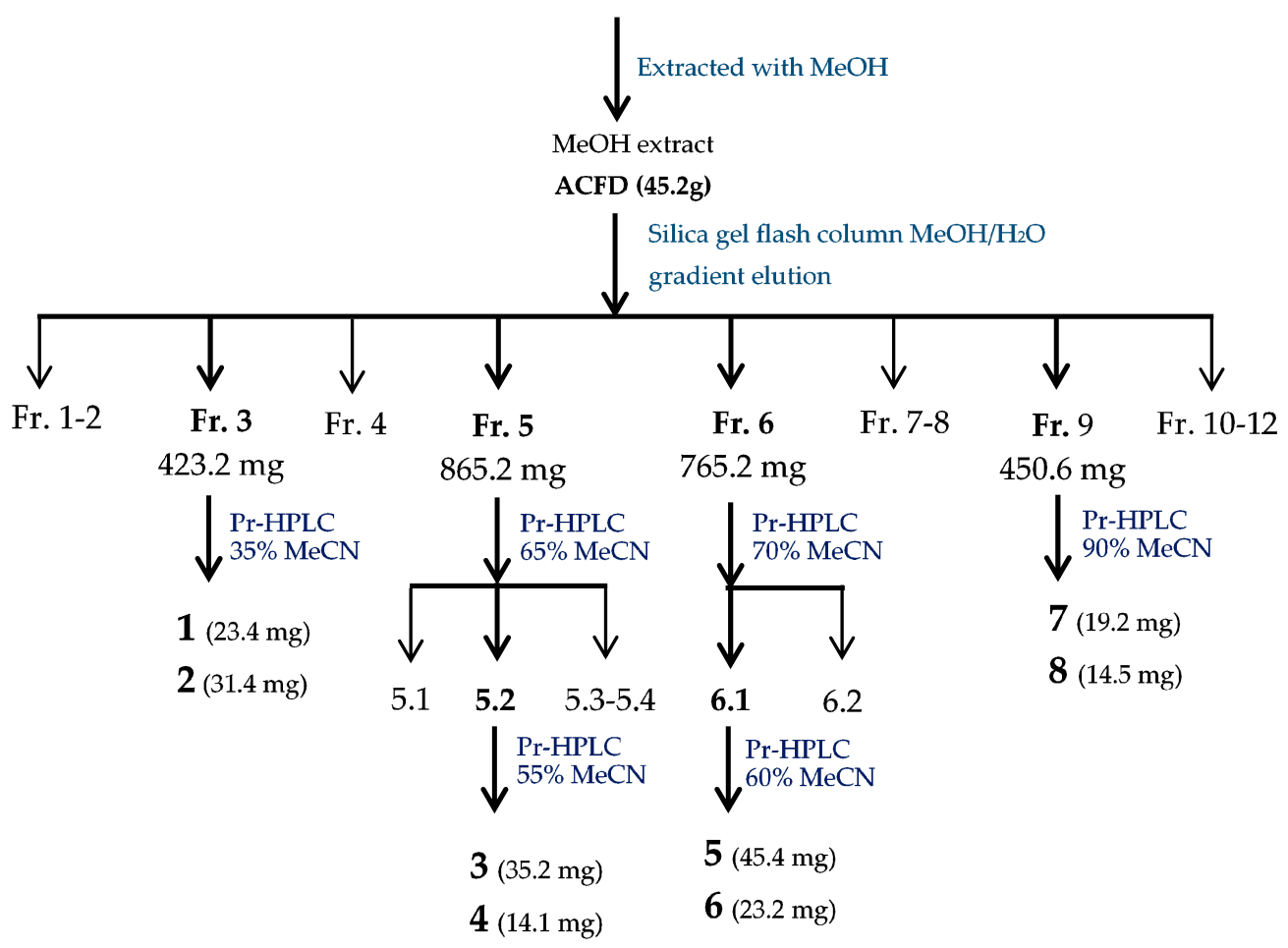

Figure 1. Flow chat of the purification process of active compounds from Antrodia cinnamomea fruiting bodies (ACFB) extract.

All purified compounds were evaluated by bioassay primarily for their aGI activity at a concentration of $0.25 \mathrm{mg} / \mathrm{mL}$; the results are presented in Figure S1c. Compounds 2, 3, 7 and 8 demonstrated good activity (89-100\%), while compounds 1 and 5 possessed activity in the range of $37-60.5 \%$, which were comparable to that of acarbose (44\%). Compounds 4 and 6 showed no significant effect against $\alpha$-glucosidase $(\leq 4 \%)$.

The eight isolated compounds $\mathbf{1 - 8}$ were identified as $25 S$-antcin $K$ (1) [33], 25R-antcin K (2) [33], dehydrosulphurenic acid (3) [34], 25S-antcin I (4) [35], 25S-antcin B (5) [33], 25R-antcin B (6) [35] dehydroeburicoic acid (7) [36] and eburicoic acid (8) [36] by analyzing NMR data, mass spectrometry and comparison to reported compounds. The ${ }^{13} \mathrm{C}-\mathrm{NMR},{ }^{1} \mathrm{H}-\mathrm{NMR}$ data are recorded in the supplementary section as Tables S1 and S2, respectively. The ${ }^{13} \mathrm{C}-\mathrm{NMR},{ }^{1} \mathrm{H}-\mathrm{NMR}$ and mass spectra of all eight identified compounds are also presented in the supplementary section as Figures S3-S26, while their chemical structures are presented in Figure 2.

Recently, compounds 1 and $\mathbf{2}$ were isolated from ACFB [30,37-39] and investigated for its reducing effects on blood glucose, total cholesterol, triglyceride and leptin levels in mice fed a high-fat diet (HFD) [30], as well as its antiproliferative activity [33,37] and inhibition against DEN-enhanced hepatocellular inflammation, fibrosis and carcinoma [38]. Compounds 3, 7 and 8 were also obtained from ACFB [31,38-40].

Compounds 1, 2 [30], 7 [28], and 8 [31] also showed hyperglycemic and antidiabetic properties via the glucose transporter 4 (GLUT4) and palmitate-treated C2C12 myotubes in mice fed a high-fat diet. Recently, compound 8 was investigated for its anti-type 1 diabetes and hypolipidemic activities [40]. However, potent aGI activity related to type 2 diabetes or obesity treatments had not been reported in the literature for all six active compounds. As such, they were determined to be new mushroom aGIs. The results of this study contributed to the catalogue of novel biological activities of A. cinnamomea, as well as its constituents. 

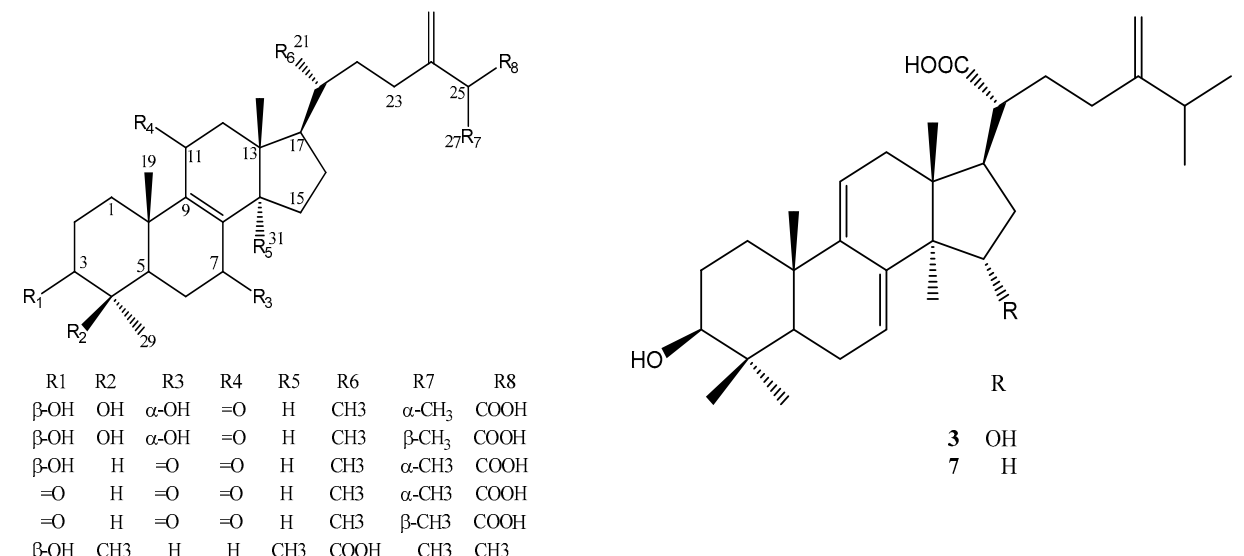

Figure 2. Chemical structures of purified active compounds. 25S-antcin K (1), 25R-antcin K (2), dehydrosulphurenic acid (3), 25S-antcin I (4), 25S-antcin B (5), 25R-antcin B (6), dehydroeburicoic acid (7) and eburicoic acid (8).

\subsection{Identification of Active Compounds on ACFB Extract Fingerprints}

To identify the active inhibitor compounds on HPLC fingerprints of ACFB extract, the crude extract, as well as all potent inhibitor compounds, were analyzed via Cosmosil $5 \mathrm{C}_{18}$-AR-II column under the same conditions. The eight isolated compounds were successfully recognized in the HPLC fingerprints of ACFB extract at the retention times (RT) of $7.282 \mathrm{~min} \mathrm{(1),} 7.543 \mathrm{~min}$ (2), $20.896 \mathrm{~min}$ (3), $21.122 \mathrm{~min}$ (4) $22.069 \mathrm{~min}$ (5), $22.084 \mathrm{~min}$ (6) $31.425 \mathrm{~min}$ (7), and $32.467 \mathrm{~min}$ (8) (Figure 3).

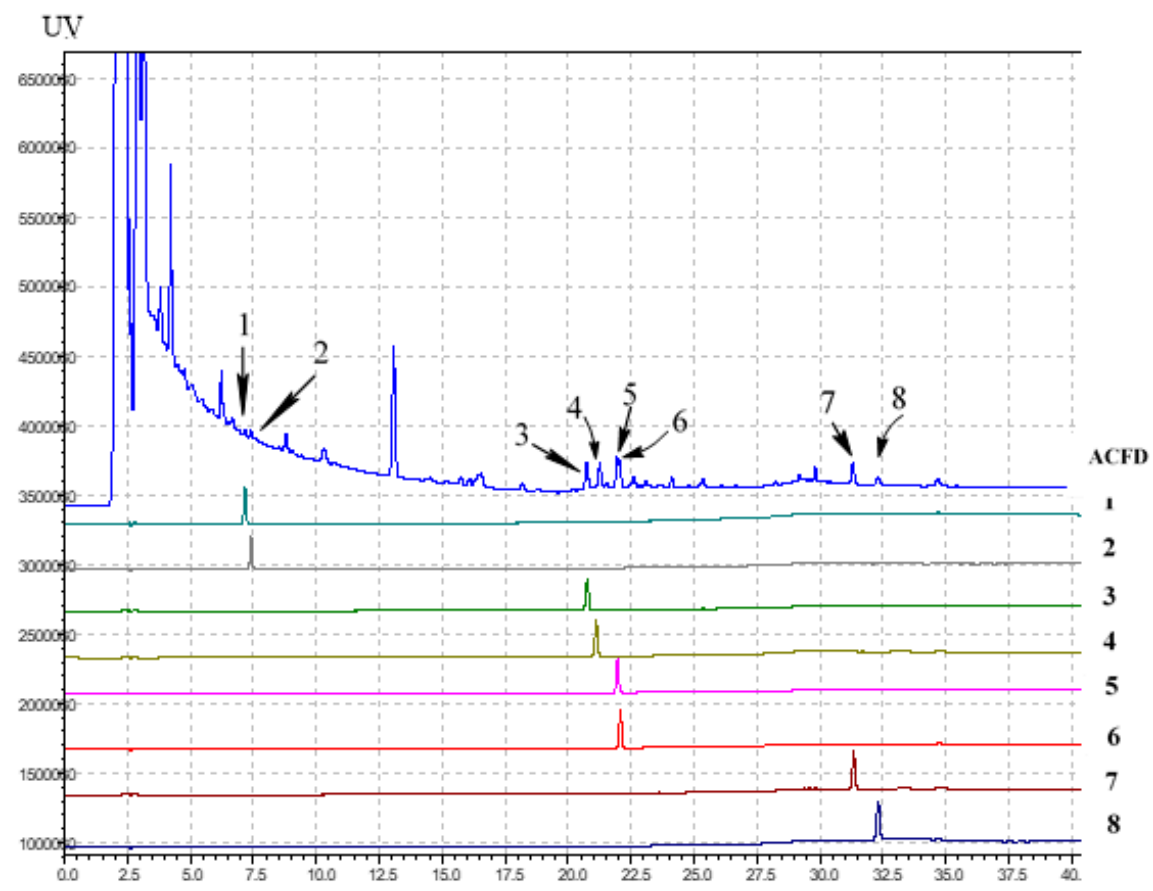

Figure 3. Identification of active inhibitors on the HPLC fingerprints of ACFB extract. 25S-antcin $\mathrm{K}$ (1), 25R-antcin K (2), dehydrosulphurenic acid (3), 25S-antcin I (4), 25S-antcin B (5), 25R-antcin B (6), dehydroeburicoic acid (7) and eburicoic acid (8). Analysis conditions: The mobile phase consisted of water containing $0.1 \%$ phosphoric acid and acetonitrile (ACN) using a gradient program of $40-50 \%$ ACN from 0-12 min, 50-60\% ACN from 12-17 min, 60-95\% ACN from 17-26 min and 95-100\% ACN from 26-50 min; separation column (Cosmosil 5C 18 -AR-II, $5 \mu \mathrm{m}, 250 \times 4.6 \mathrm{~mm}$ i.d.) was employed, eluting at a flow rate of $1.0 \mathrm{~mL} / \mathrm{min}$ at $35^{\circ} \mathrm{C}$; the real-time UV absorption was detected at $210 \mathrm{~nm}$. 
Almost all of the active inhibitors could be clearly observed in the HPLC fingerprints of the crude extract. These results indicate that they should be major constituents of ACFB extract. As such, HPLC analysis coupled with inhibitory assay may be a convenient, rapid and precise method to standardize ACFB extracts from different sources in order to select good material for T2D management.

\subsection{Inhibitory Activity Comparison of $\alpha$-Glucosidase Inhibitor Compounds}

To evaluate the most potent aGI compounds, all identified compounds and acarbose were tested for activity over a large concentration range of $0.02-0.25 \mu \mathrm{g} / \mathrm{mL}$. Activity was expressed as $\mathrm{EC}_{50}$ $(\mathrm{mg} / \mathrm{mL})$ and inhibition (\%), as presented in Table 2. Of the tested inhibitors, three compounds, dehydrosulphurenic acid (3), dehydroeburicoic acid (7) and eburicoic acid (8), demonstrated the greatest effect against $\alpha$-glucosidase due to their small $\mathrm{EC}_{50}$ values $(0.012-0.05 \mathrm{mg} / \mathrm{mL}$, ranked at $d$ level), and greatest max inhibition at $0.25 \mathrm{mg} / \mathrm{mL}(98-100 \%$, ranked at $a$ level). The compounds $25 R$-antcin K (2) and 25S-antcin B (5) were also potent inhibitors since their activity was stronger than that of the control, while compound 1 showed the weakest activity.

Table 2. $\alpha$-Glucosidase inhibitory activity of isolated compounds from ACFB extract.

\begin{tabular}{|c|c|c|c|}
\hline Compd No. & Compound & $\mathrm{EC}_{50}(\mathrm{mg} / \mathrm{mL})$ & Inhibition $(\%)$ at $0.25 \mathrm{mg} / \mathrm{mL}$ \\
\hline 1 & 25S-antcin K & $\geq 0.25^{\mathrm{ND}}$ & $37 \pm 0.91^{\mathrm{d}}$ \\
\hline 2 & $25 R$-antcin $\mathrm{K}$ & $0.054 \pm 0.0004^{\mathrm{c}}$ & $89 \pm 2.03^{b}$ \\
\hline 3 & Dehydrosulphurenic acid & $0.025 \pm 0.0008^{d}$ & $99 \pm 0.92^{a}$ \\
\hline 5 & $25 S$-antcin B & $0.21 \pm 0.0076^{\mathrm{b}}$ & $61 \pm 2.27^{c}$ \\
\hline 7 & Dehydroeburicoic acid & $0.018 \pm 0.0002^{\mathrm{d}}$ & $100 \pm 1.87^{a}$ \\
\hline \multirow[t]{3}{*}{8} & Eburicoic acid & $0.012 \pm 0.0004 \mathrm{~d}$ & $98 \pm 2.33^{a}$ \\
\hline & Acarbose (positive control) & $0.278 \pm 0.0023^{a}$ & $44 \pm 0.57^{\mathrm{d}}$ \\
\hline & Coefficient of variation $(\%)$ & 5.964010 & 4.021327 \\
\hline
\end{tabular}

All inhibitors were tested within a concentration range of $0.02-0.25 \mu \mathrm{g} / \mathrm{mL}$; the means of inhibitory activity, including $\mathrm{EC}_{50}(\mathrm{mg} / \mathrm{mL})$, and inhibition (\%) values with the same letters in the same column are not significantly different, based on analysis of Duncan's multiple range test at $\alpha=0.01$, using SAS version 9.4 (SAS Institute Taiwan Ltd., Taipei, Taiwan). ND: Not detected.

The potent inhibitory activities of the tested inhibitors, in order of decreasing activity, are as follows: Eburicoic acid (8) $\geq$ dehydroeburicoic acid (7) $\geq$ dehydrosulphurenic acid (3) $\geq 25 R$-antcin $\mathrm{K}(2) \geq 25 S$-antcin $\mathrm{B}(5) \geq$ acarbose $\geq 25 S$-antcin $\mathrm{K}(\mathbf{1})$, where " $\geq$ " indicates that there is no significantly higher inhibitory activity between the two inhibitors, based on Duncan's multiple range test. The results indicate that almost all inhibitors isolated from ACFB extract showed higher activity than acarbose. As such, this edible medicinal mushroom may have potential as a safe and natural source of aGIs for effective management of T2D.

\section{5. $p H$ and Thermal Stabilities of A. cinnamomea a-Glucosidase Inhibitors}

To determine $\mathrm{pH}$ stability of $A$. cinnamomea aGIs, each sample was pre-treated with a large $\mathrm{pH}$ range of 2-11 for $30 \mathrm{~min}$ before evaluating inhibition at $\mathrm{pH} 7$, using the bioassay techniques described in the methods section. As shown in Figure 4a, ACFB extract and the purified compounds (3, 5, 7, and 8) possessed high $\mathrm{pH}$ stability with great relative activity of 80-117\%. Compound 1 demonstrated high stability in acidic $\mathrm{pH}$ treatment $(\mathrm{pH} 2-4)$ but very weak activity in the $\mathrm{pH}$ range treatment from 5-11, while compound 2 showed good activity in the alkaline pH but weak activity in acidic condition treatment. It was suggested that $\mathrm{pH}$ stability is an important characteristic that should be considered when evaluating aGIs. A potential aGI should have acceptable or high $\mathrm{pH}$ stability, especially at acidic $\mathrm{pH}$, since the $\mathrm{pH}$ in the gastrointestinal tract (stomach) is normally acidic $[1,5,14]$. Recently, the acidic $\mathrm{pH}$ stability of some inhibitors was reported, such as aGIs from Euonymus laxiflorus Champ which showed low relative activity of $48 \%$ at $\mathrm{pH} 4$ and aGIs from Dalbergia tonkinensis which demonstrated an acceptable relative activity of $80-83 \%$ at $\mathrm{pH} 2-4$, while fermented nutrient broth and fermented squid pens by Paenibacillus sp. had potent relative activities of $86-97 \%$ (pH 1-4) and 89-95\% 
(pH 2-4), respectively. In this study, ACFB extract and its purified compounds, except compound 2, demonstrated comparable or higher stability than those of previous reports with a relative activity of $85-110 \%$ at an acidic $\mathrm{pH}$ of $2-4$.

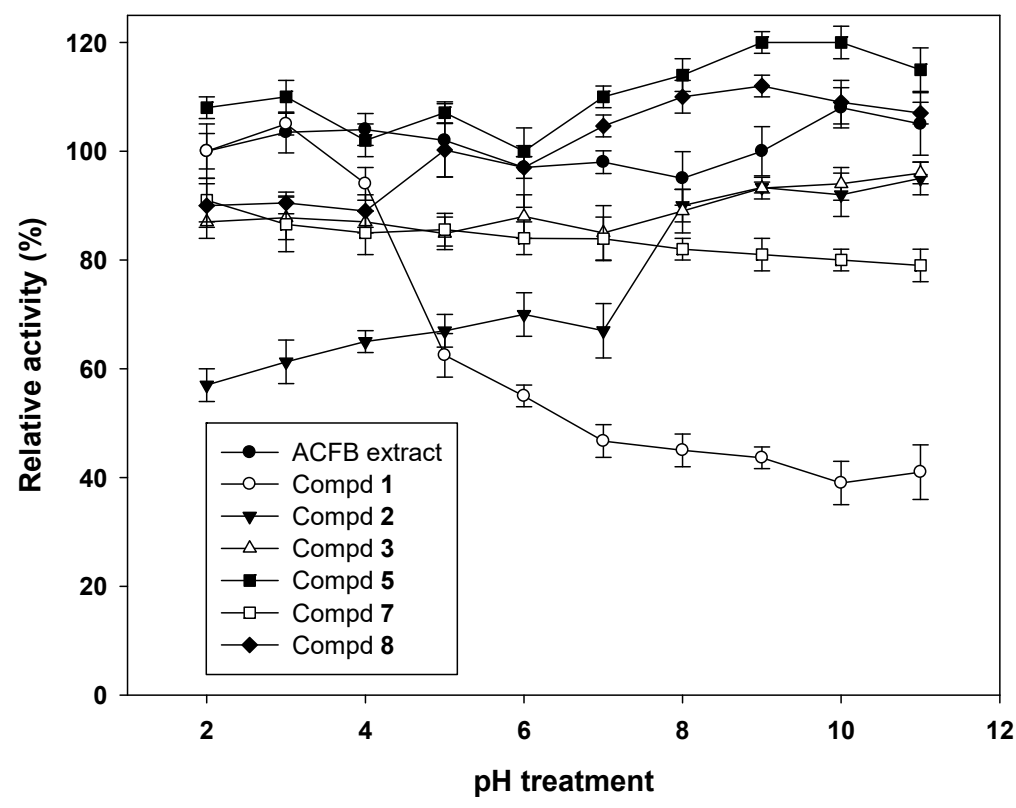

(a)

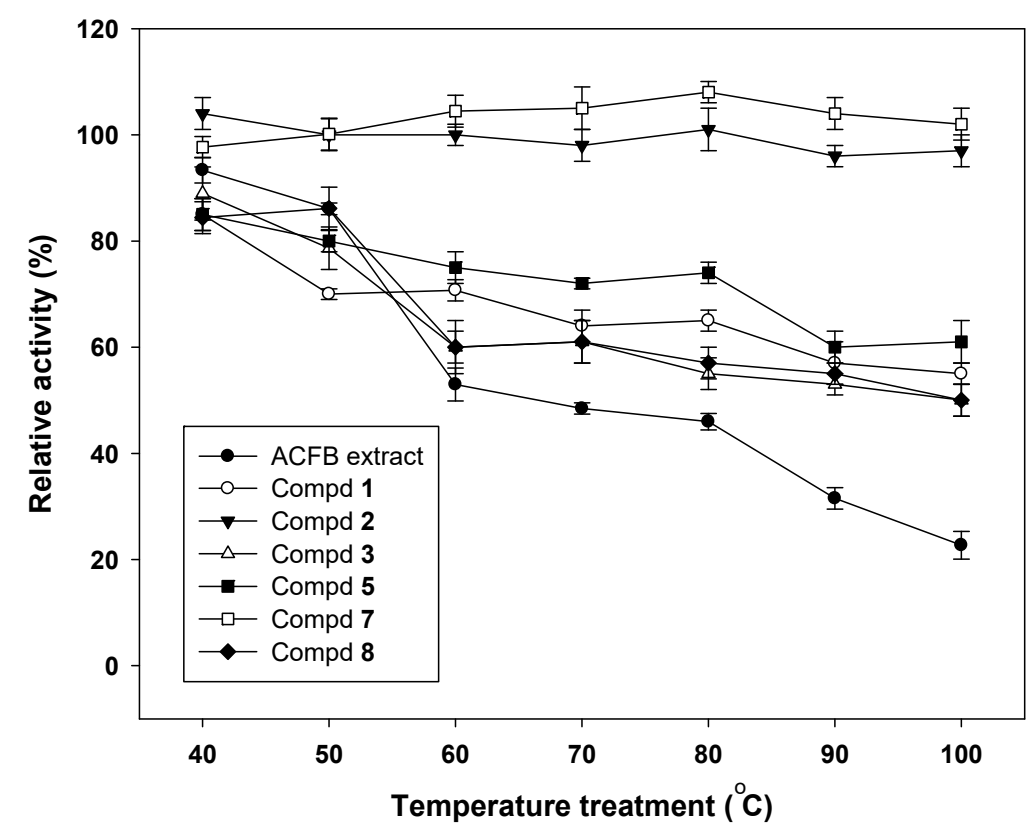

(b)

Figure 4. The $\mathrm{pH}$ and thermal stabilities of ACFB extract and the purified compounds. The $\mathrm{pH}(\mathrm{a})$ and thermal (b) stability of ACFB and its purified compounds were tested by treating the samples with a range of $\mathrm{pH}(2-11)$ and temperatures $\left(40-100^{\circ} \mathrm{C}\right)$ for $30 \mathrm{~min}$, respectively. The $\alpha$-glucosidase inhibition of treated samples was tested under the same conditions, using the bioassay mentioned in the methods section. Tests were performed in triplicate. Results are means \pm SD.

The thermal stability of aGIs from ACFB was evaluated by pre-treating samples to a range of temperatures $\left(40-100{ }^{\circ} \mathrm{C}\right)$ for $30 \mathrm{~min}$, before inhibition was tested at $37^{\circ} \mathrm{C}$ by bioassay. The results 
are presented in Figure 4b. Compounds 2 and 7 showed good thermal stability at all the treated temperatures with high relative activity of $96-108^{\circ} \mathrm{C}$. However, ACFB extract and other identified compounds were only stable at $40-50{ }^{\circ} \mathrm{C}$ with relative activity of $70.2-93.3 \%$. The results suggest that ACFB should be not treated higher than $50{ }^{\circ} \mathrm{C}$ to obtain aGIs for use in folk medicine or to prepare the extract for purification, since it may reduce significant inhibitory activity. In comparison, aGIs from ACFB except 2 and 7 demonstrated lower thermal stability (22.7-93.3\%) than those of aGIs from E. laxiflorus Champ. (75-100\%) [5], fermented nutrient broth (92-99\%) [14] or squid pens fermented by Paenibacillus sp. (91-99\%) [1].

\section{Materials and Methods}

\subsection{Materials}

The fruiting bodies of $A$. cinnamomea were collected from the mountains of Kavulungan, Taitung, Taiwan in March 2017. Saccharomyces cerevisiae $\alpha$-glucosidase and acarbose were purchased from Sigma Chemical Co., St. Louis City, MO, USA. The substrate $p$ NPG was purchased from Sigma Aldrich, St. Louis, MO, USA. Solvents, reagents and other chemicals were obtained at the highest grade available

\subsection{Determination of $\alpha$-Glucosidase Inhibitory Activity}

The $\alpha$-glucosidase inhibition was performed following the assay methods described by Nguyen et al. (2018) [15], with slight modifications. In brief, $50 \mu \mathrm{L}$ sample solutions were mixed with $100 \mu \mathrm{L}$ $\alpha$-glucosidase, then incubated at $37{ }^{\circ} \mathrm{C}$ for $20 \mathrm{~min}$. A total of $50 \mu \mathrm{L}$ of $p$-NPG (10 mmol/L) was added to each mixture to start a reaction. The mixture was kept at $37^{\circ} \mathrm{C}$ for 30 min before $100 \mu \mathrm{L}$ $\mathrm{Na}_{2} \mathrm{CO}_{3}(1 \mathrm{~mol} / \mathrm{L})$ was added to stop the reaction. The final mixture was then measured at $410 \mathrm{~nm}(\mathrm{~A})$. The control group was also prepared as described above but with the use of $50 \mu \mathrm{L}, 0.1 \mathrm{~mol} / \mathrm{L}$ potassium phosphate buffer ( $\mathrm{pH} 7$ ) instead of the sample solution; its absorbance was also recorded at $410 \mathrm{~nm}$ (B). The $\alpha$-glucosidase inhibition (\%) was estimated using the following equation:

$$
\alpha \text {-glucosidase inhibition }(\%)=(B-A) / B \times 100
$$

Inhibition activity was also expressed as an $\mathrm{EC}_{50}$ value, which is defined as the concentration of inhibitor that inhibits 50\% of enzyme activity [15]. The crude extract, fractions and pure compounds were prepared in methanol then diluted in $0.1 \mathrm{~mol} / \mathrm{L}$ potassium phosphate buffer ( $\mathrm{pH} 7)$. The enzyme solution was also prepared in $0.1 \mathrm{~mol} / \mathrm{L}$ potassium phosphate buffer ( $\mathrm{pH} 7)$. Acarbose was prepared in distilled water then also diluted in the same buffer.

\subsection{Extraction and Purification}

General experimental procedures: High resolution electronic ionization mass spectrometry (HREIMS) data were measured using a Shimadzu IT-TOF HR mass spectrometer (Shimadzu, Kyoto, Japan). Nuclear magnetic resonance (NMR) spectra were recorded on a Bruker AC-400 FT-NMR (Bruker BioSpin, Rheinstetten, Germany) using $\mathrm{C}_{5} \mathrm{D}_{5} \mathrm{~N}$ (pyridine- $d_{5}$ ) as solvent. Silica gel 60 (Merck 70-230 and 230-400 mesh, Merck, Darmstadt, Germany) were used for column chromatography, and pre-coated silica gel (Merck 60 F-254) plates were used for TLC. The spots on TLC were detected by spraying with an anisaldehyde-sulfuric acid solution and then heating at $100{ }^{\circ} \mathrm{C}$. HPLC separations were performed on a Shimadzu LC-2040C series apparatus (Shimadzu, Kyoto, Japan) with a photodiode array detector, equipped with a $250 \times 4.6 \mathrm{~mm}$ i.d. preparative Cosmosil 5C $18 \mathrm{AR}-\mathrm{II}$ column (Nacalai Tesque, Inc., Kyoto, Japan).

Extraction and isolation: Dried $A$. cinnamomea fruiting bodies (200 g) were extracted five times with $\mathrm{MeOH}(10 \mathrm{~L})$ at $50{ }^{\circ} \mathrm{C}$ for $12 \mathrm{~h}$, then concentrated under reduced pressure. The MeOH extract $(45.2 \mathrm{~g})$ was separated by silica gel flash column $(70-230$ mesh, $15 \times 10 \mathrm{~cm}, 0.9 \mathrm{~kg})$ with a gradient 
solvent system of $\mathrm{CH}_{2} \mathrm{Cl}_{2} 100 \%$ to $\mathrm{MeOH} 100 \%$, to provide 12 fractions (ACFB.1-ACFB.12). ACFB.3 (423.2 mg) was purified by preparative HPLC (Cosmosil 5C 18 -AR-II, $5 \mu \mathrm{m}, 250 \times 20 \mathrm{~mm}$ i.d., $\mathrm{MeCN} / \mathrm{H}_{2} \mathrm{O}$ containing $0.1 \%$ formic acid, $35: 65$, flow rate $10 \mathrm{~mL} / \mathrm{min}$ ) to produce $25 \mathrm{~S}$-antcin $\mathrm{K}$ $\left(\mathbf{1}, 23.4 \mathrm{mg},{ }_{\mathrm{R}}^{t}=7.282 \mathrm{~min}\right)$ and $25 \mathrm{R}$-antcin $\mathrm{K}\left(\mathbf{2}, 31.4 \mathrm{mg},{ }_{\mathrm{R}}{ }_{\mathrm{R}}=7.543 \mathrm{~min}\right)$. ACFB.5 (865.2 $\left.\mathrm{mg}\right)$ was purified by preparative HPLC (Cosmosil 5C $\mathrm{C}_{18}$-AR-II, $5 \mu \mathrm{m}, 250 \times 20 \mathrm{~mm}$ i.d., MeCN/H2O containing 0.1\% formic acid, 65:35, flow rate $10 \mathrm{~mL} / \mathrm{min}$ ) to produce four subfractions (ACFB.5.1-ACFB.5.4). ACFB.5.2 (232.1 mg) was further purified by recycled preparative HPLC (Cosmosil 5C C $_{18}$-AR-II, $5 \mu \mathrm{m}$, $250 \times 20 \mathrm{~mm}$ i.d., $\mathrm{MeCN} / \mathrm{H} 2 \mathrm{O}$ containing $0.1 \%$ formic acid, 55:45, flow rate $10 \mathrm{~mL} / \mathrm{min}$, recycled 8 times) to produce dehydrosulphurenic acid $\left(3,35.2 \mathrm{mg},{ }^{t} \mathrm{R}=20.896 \mathrm{~min}\right)$ and $25 S$-antcin $\mathrm{I}(4,14.1 \mathrm{mg}$, $\left.{ }_{\mathrm{R}}{ }_{\mathrm{R}}=21.122 \mathrm{~min}\right)$. ACFB.6 (765.2 mg) was purified by preparative HPLC (Cosmosil 5C 18 -AR-II, $5 \mu \mathrm{m}$, $250 \times 20 \mathrm{~mm}$ i.d., $\mathrm{MeCN} / \mathrm{H}_{2} \mathrm{O}$ containing $0.1 \%$ formic acid, $70: 30$, flow rate $10 \mathrm{~mL} / \mathrm{min}$ ) to produce two subfractions: ACFB.6.1 and ACFB.6.2. ACFB.6.1 was further purified by recycled preparative HPLC (Cosmosil 5C $\mathrm{C}_{18}$-AR-II, $5 \mu \mathrm{m}, 250 \times 20 \mathrm{~mm}$ i.d., $\mathrm{MeCN} / \mathrm{H}_{2} \mathrm{O}$ containing 0.1\% formic acid, 60:40, flow rate $10 \mathrm{~mL} / \mathrm{min}$, recycled 6 times) to produce $25 S$-antcin $\mathrm{B}\left(5,45.4 \mathrm{mg},{ }_{\mathrm{R}}^{t}=22.069 \mathrm{~min}\right)$ and $25 R$-antcin $\mathrm{B}\left(6,23.2 \mathrm{mg},{ }_{\mathrm{R}}=22.084 \mathrm{~min}\right)$. ACFB.9 $(450.6 \mathrm{mg})$ was purified by preparative HPLC (Cosmosil 5C 18 -AR-II, $5 \mu \mathrm{m}, 250 \times 20 \mathrm{~mm}$ i.d., $\mathrm{MeCN} / \mathrm{H}_{2} \mathrm{O}$ containing $0.1 \%$ formic acid, 90:10, flow rate $10 \mathrm{~mL} / \mathrm{min})$ to produce dehydroeburicoic acid $\left(7,19.2 \mathrm{mg},{ }_{\mathrm{R}}=31.425 \mathrm{~min}\right)$ and eburicoic acid $(8$, $\left.14.5 \mathrm{mg},{ }_{\mathrm{R}}=32.467 \mathrm{~min}\right)$.

\subsection{HPLC Analysis}

Separation column (Cosmosil 5C 18 -AR-II, $5 \mu \mathrm{m}, 250 \times 4.6 \mathrm{~mm}$ i.d.) was used, while eluting at a flow rate of $1.0 \mathrm{~mL} / \mathrm{min}$ at $35{ }^{\circ} \mathrm{C}$. The mobile phase consisted of water containing $0.1 \%$ phosphoric acid and acetonitrile (ACN), using a gradient program of $40-50 \%$ ACN from $0-12 \mathrm{~min}, 50-60 \% \mathrm{ACN}$ from 12-17 $\mathrm{min}, 60-95 \%$ ACN from $17-26 \mathrm{~min}$ and $95-100 \% \mathrm{ACN}$ from $26-50 \mathrm{~min}$. The real-time UV absorption was detected at $210 \mathrm{~nm}$. Each isolated compound was accurately weighed and dissolved in $\mathrm{MeOH}$; the terminate concentration was ca. $1.0 \mathrm{mg} / \mathrm{mL}$. ACFB extract was dried under vacuum, accurately weighed to about $10 \mathrm{mg}$, then dissolved in $\mathrm{MeOH}$, in a $1.0 \mathrm{~mL}$ volumetric flask. The sample solutions were all filtered with $0.45 \mu \mathrm{m}$ PVDF membrane filter (Millipore Sigma, Billerica, MA, USA) before use. The injection volumes of the compound and ACFB were $1 \mu \mathrm{L}$ and $10 \mu \mathrm{L}$, respectively.

\subsection{Determination of $\mathrm{pH}$ and Thermal Stabilities of A. cinnamomea a-Glucosidase Inhibitors}

pH measurement was performed as per the methods described by Nguyen et al. (2017) [14] with slight modifications, samples were pre-treated with a large $\mathrm{pH}$ range of 2-11 for $30 \mathrm{~min}$ at $37^{\circ} \mathrm{C}$. The buffer systems $(0.1 \mathrm{~mol} / \mathrm{L})$ used were glycine $\mathrm{HCl}(\mathrm{pH} 2-4)$, sodium acetate $(\mathrm{pH} 5)$, sodium phosphate ( $\mathrm{pH} 6-8)$ and sodium carbonate $(\mathrm{pH} 9-11)$. The $\mathrm{pH}$ of treated sample solution was adjusted to $\mathrm{pH} 7$ by adding $0.25 \mathrm{~mol} / \mathrm{L}$ potassium phosphate buffer $(\mathrm{pH}$ ) before testing activity. The thermal stability of ACFB aGIs was also examined by pre-treating samples to a range of temperatures $\left(40-100{ }^{\circ} \mathrm{C}\right)$ for $30 \mathrm{~min}$, before $\alpha$-glucosidase inhibitory activity was tested at $37^{\circ} \mathrm{C}$ [5] using the bioassay above.

\subsection{Statistical Analysis}

The differences between the means of inhibition (\%) and $\mathrm{EC}_{50}$ values was analyzed with the use of SAS (Statistical Analysis Software) version 9.4, provided by SAS Institute Taiwan Ltd. (Taipei, Taiwan), using Duncan's multiple range test $(\alpha=0.01)$. All tests were performed in triplicate $(n=3)$.

\section{Conclusions}

The $\mathrm{MeOH}$ extract of ACFB was investigated for the first time for its potent in-vitro antidiabetic effect, characterized using an $\alpha$-glucosidase inhibitory activity assay. ACFB demonstrated high $\mathrm{pH}$ stability ( $\mathrm{pH} 2-11)$ and thermostable properties at $40-50{ }^{\circ} \mathrm{C}$. Five active compounds, including $25 R$-antcin K (2), dehydrosulphurenic acid (3), 25S-antcin B (5), dehydroeburicoic acid (7) and eburicoic 
acid (8), were successfully isolated and identified from ACFB, showing stronger $\alpha$-glucosidase inhibitory effect and higher activity $\left(\mathrm{EC}_{50}=0.025-0.21 \mathrm{mg} / \mathrm{mL}\right)$ than acarbose $\left(\mathrm{EC}_{50}=0.278 \mathrm{mg} / \mathrm{mL}\right)$. Notably, these novel compounds were investigated for the first time for their $\alpha$-glucosidase inhibitory effect in this study. The results of this study contributed to the catalogue of novel biological activities of AC, as well as its constituents. The results also suggest that ACFB is a highly rich, safe and natural source of bioactive constituents that may be developed as drugs or health foods with potential antidiabetic effects.

Supplementary Materials: The supplementary materials are available online.

Author Contributions: Conceptualization: S.-L.W., V.B.N. and Y.-H.K.; Methodology: V.B.N. and H.T.H.; Software: V.B.N. and H.T.H.; Validation: S.-L.W. and Y.-H.K.; Formal analysis: V.B.N., S.-L.W. and Y.-H.K.; Investigation: V.B.N. and H.T.H.; Resources: Y.-H.K., S.-L.W., and V.B.N.; Data curation: V.B.N. and H.T.H.; Writing original draft: V.B.N.; Writing review \& editing: S.-L.W., V.B.N., H.T.H. and Y.-H.K.; Visualization: V.B.N., S.-L.W. and Y.-H.K.; Supervision: Y.-H.K. and S.-L.W.; Project administration: S.-L.W. and Y.-H.K.

Funding: This work was supported in part by a grant from the Ministry of Science and Technology, Taiwan (MOST 106-2320-B-032-001-MY3), the Ministry of Education, Taiwan (TKU 0657010), the Ministry of Science and Technology, Taiwan (MOST104-2320-B-077-006-MY3, MOST107-2320-B-077-003-MY3), and Ministry of Health and Welfare, Taiwan (MM10601-0160, MM10701-0117).

Conflicts of Interest: The authors declare no conflict of interest.

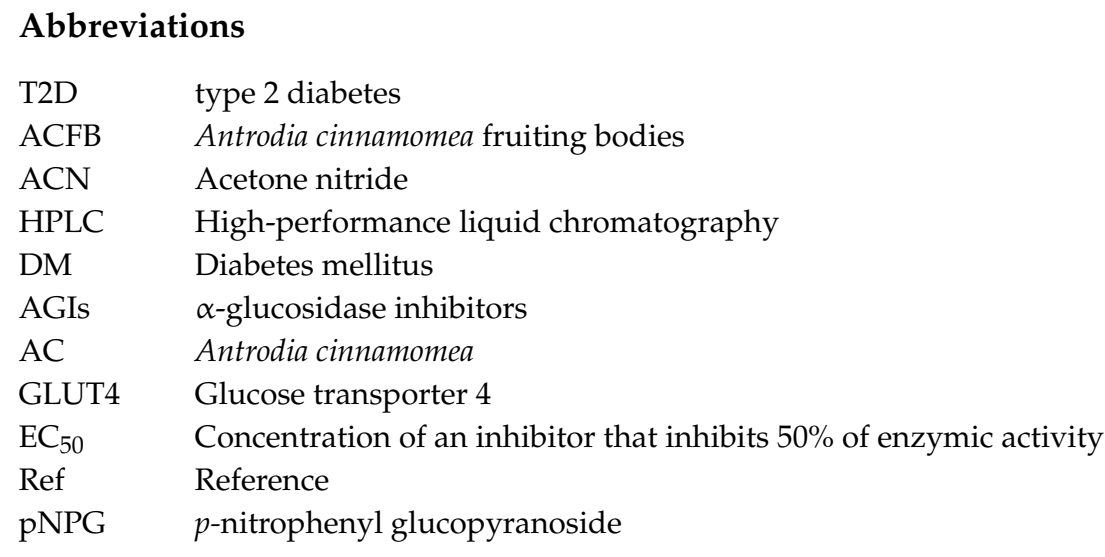

\section{References}

1. Nguyen, V.B.; Nguyen, A.D.; Wang, S.L. Utilization of fishery processing by-product squid pens for $\alpha$-glucosidase inhibitors production by Paenibacillus sp. Mar. Drugs 2017, 15, 274. [CrossRef] [PubMed]

2. Gerstein, H.C.; Miller, M.E.; Byington, R.P.; Goff, D.C., Jr.; Bigger, J.T.; Buse, J.B.; Cushman, W.C.; Genuth, S.; Ismail-Beigi, F.; Grimm, R.H., Jr. Effects of intensive glucose lowering in type 2 diabetes. N. Engl. J. Med. 2008, 358, 2545-2559. [PubMed]

3. Ley, S.H.; Hamdy, O.; Mohan, V.; Hu, F.B. Prevention and management of type 2 diabetes: Dietary components and nutritional strategies. Lancet 2014, 383, 1999-2007. [CrossRef]

4. DeMelo, E.B.; Gomes, A.; Carvalha, I. $\alpha$-and $\beta$-Glucosidase inhibitors: Chemical structure and biological activity. J. Tetrahedr. 2006, 62, 10277-10302.

5. Nguyen, V.B.; Nguyen, Q.V.; Nguyen, A.D.; Wang, S.L. Screening and evaluation of $\alpha$-glucosidase inhibitors from indigenous medicinal plants in Dak Lak Province, Vietnam. Res. Chem. Intermed. 2017, 43, 3599-3612. [CrossRef]

6. Tan, C.; Wang, Q.; Luo, C.; Chen, S.; Li, Q.; Li, P. Yeast $\alpha$-glucosidase inhibitory phenolic compounds isolated from Gynura medica leaf. Int. J. Mol. Sci. 2013, 14, 2551-2558. [CrossRef] [PubMed]

7. Nguyen, Q.V.; Nguyen, V.B.; Eun, J.B.; Wang, S.L.; Nguyen, D.H.; Tran, T.N.; Nguyen, A.D. Anti-oxidant and antidiabetic effect of some medicinal plants belong to Terminalia species collected in Dak Lak Province, Vietnam. Res. Chem. Intermed. 2016, 42, 5859-5871. [CrossRef] 
8. Nguyen, Q.V.; Wang, S.L.; Nguyen, A.D. In vitro $\alpha$-glucosidase and $\alpha$-amylase inhibition, and in vivo anti-hyperglycemic effects of Psidium littorale Raddi leaf extract. Res. Chem. Intermed. 2018, 44, 1745-1753. [CrossRef]

9. Nguyen, V.B.; Wang, S.L.; Nhan, N.T.; Nguyen, T.H.; Nguyen, N.P.D.; Nghi, D.H.; Cuong, N.M. New records of potent in-vitro antidiabetic properties of Dalbergia tonkinensis heartwood and the bioactivity-guided isolation of active compounds. Molecules 2018, 23, 1589. [CrossRef] [PubMed]

10. Nguyen, V.B.; Wang, S.L.; Nguyen, T.H.; Nguyen, M.T.; Doan, C.T.; Tran, T.N.; Lin, Z.H.; Nguyen, Q.V.; Kuo, Y.H.; Nguyen, A.D. Novel potent hypoglycemic compounds from Euonymus laxiflorus Champ. and their effect on reducing plasma glucose in an ICR mouse model. Molecules 2018, 23, 1928. [CrossRef] [PubMed]

11. Nguyen, V.B.; Wang, S.L. Reclamation of marine chitinous materials for the production of $\alpha$-glucosidase inhibitors via microbial conversion. Mar. Drugs 2017, 15, 350. [CrossRef] [PubMed]

12. Wang, S.L.; Su, Y.C.; Nguyen, V.B.; Nguyen, A.D. Reclamation of shrimp heads for the production of $\alpha$-glucosidase inhibitors by Staphylococcus sp. TKU043. Res. Chem. Intermed. 2018, 44, 4929-4937. [CrossRef]

13. Hsu, C.H.; Nguyen, V.B.; Nguyen, A.D.; Wang, S.L. Conversion of shrimp heads to $\alpha$-glucosidase inhibitors via co-culture of Bacillus mycoides TKU040 and Rhizobium sp. TKU041. Res. Chem. Intermed. 2017, 44, 4597-4607. [CrossRef]

14. Nguyen, V.B.; Nguyen, A.D.; Kuo, Y.H.; Wang, S.L. Biosynthesis of $\alpha$-glucosidase inhibitors by a newly isolated bacterium, Paenibacillus sp. TKU042 and its effect on reducing plasma glucose in mouse model. Int. J. Mol. Sci. 2017, 18, 700. [CrossRef] [PubMed]

15. Nguyen, V.B.; Wang, S.L. New novel $\alpha$-glucosidase inhibitors produced by microbial conversion. Process Biochem. 2018, 65, 228-232. [CrossRef]

16. Bae, S.M.; Han, S.M.; Lee, Y.H.; Jung, Y.K.; Ji, J.H.; Lee, J.S. Extraction and characterization of an anti-hyperglycemic $\alpha$-glucosidase inhibitor from edible mushroom, Pleurotus cornucopiae. Microbiol. Biotechnol. Lett. 2016, 44, 124-129. [CrossRef]

17. Im, K.H.; Nguyen, T.K.; Choi, J.; Lee, T.S. In vitro antioxidant, anti-diabetes, anti-dementia, and inflammation inhibitory effect of Trametes pubescens fruiting body extracts. Molecules 2016, 21, 639. [CrossRef] [PubMed]

18. Shoba, K.; Krishnakumari, S. In vitro studies on antioxidant and antidiabetic activity of Pleurotus eous mushroom in methanol and aqueous extract. Asian J. Pharm. Clin. Res. 2018, 11, 259-285.

19. Su, C.H.; Lai, M.N.; $\mathrm{Ng}$, L.T. Inhibitory effects of medicinal mushrooms on $\alpha$-amylase and $\alpha$-glucosidase-enzymes related to hyperglycemia. Food Funct. 2013, 4, 644-649. [CrossRef] [PubMed]

20. Martel, J.; Ojcius, D.M.; Lai, H.C.; Young, J.D. Mushrooms-From cuisine to clinic. Biomed. J. 2014, 37, 343-344. [PubMed]

21. Wasser, S.P. Medicinal mushroom science: Current perspectives, advances, evidences, and challenges. Biomed. J. 2014, 37, 345-356. [CrossRef] [PubMed]

22. Chang, C.J.; Lu, C.C.; Lin, C.S.; Martel, J.; Ko, Y.F.; Ojcius, D.M.; Wu, T.R.; Tsai, Y.H.; Yeh, T.S.; Lu, J.J.; et al. Antrodia cinnamomea reduces obesity and modulates the gut microbiota in high-fat diet-fed mice. Int. J. Obes. 2018, 42, 231-243. [CrossRef] [PubMed]

23. Kumar, K.J.; Chu, F.H.; Hsieh, H.W.; Liao, J.W.; Li, W.H.; Lin, J.C.; Shaw, J.F.; Wang, S.Y. Antroquinonol from ethanolic extract of mycelium of Antrodia cinnamomea protects hepatic cells from ethanol-induced oxidative stress through Nrf-2 activation. J. Ethnopharmacol. 2011, 14, 168-177. [CrossRef] [PubMed]

24. Liu, Y.W.; Lu, K.H.; Ho, C.T.; Sheen, L.Y. Protective effects of Antrodia cinnamomea against liver injury. J. Tread Comp. Med. 2012, 2, 284-294. [CrossRef]

25. Lu, M.C.; El-Shazly, M.; Wu, T.Y.; Du, Y.C.; Chang, T.T.; Chen, C.F.; Hsu, Y.M.; Lai, K.H.; Chiu, C.P.; Chang, F.R.; et al. Recent research and development of Antrodia cinnamomea. Pharmacol. Ther. 2013, 139, 124-156. [CrossRef] [PubMed]

26. Yue, P.Y.; Wong, Y.Y.; Chan, T.Y.; Law, C.K.; Tsoi, Y.K.; Leung, K.S. Review of biological and pharmacological activities of the endemic Taiwanese bitter medicinal mushroom, Antrodia camphorata (M. Zang et C. H. Su) Sh. H. Wu et al. (Higher Basidiomycetes). Int. J. Med. Mushroom. 2012, 14, 241-256. [CrossRef]

27. Lai, M.N.; Ko, H.J.; Ng, L.T. Hypolipidemic effects of Antrodia cinnamomea extracts in high-fat diet-fed hamsters. J. Food. Biochem. 2012, 36, 233-239. [CrossRef]

28. Kuo, Y.H.; Lin, C.H.; Shih, C.C. Antidiabetic and antihyperlipidemic properties of a triterpenoid compound, dehydroeburicoic acid, from Antrodia camphorata in vitro and in streptozotocin-induced mice. J. Agric. Food. Chem. 2015, 63, 10140-10151. [CrossRef] [PubMed] 
29. Kuo, Y.H.; Lin, C.H.; Shih, C.C. Ergostatrien-3beta-ol from Antrodia camphorata inhibits diabetes and hyperlipidemia in high-fat-diet treated mice via regulation of hepatic related genes, glucose transporter 4 , and AMP-activated protein kinase phosphorylation. J. Agric. Food. Chem. 2015, 63, 2479-2489. [CrossRef] [PubMed]

30. Kuo, Y.H.; Lin, C.H.; Shih, C.C.; Yang, C.S. Ancin K, a triterpenoid compound from Antrodia camphorata, displays antidiabetic and antihyperlipidemic effects via glucose transporter 4 and AMP-activated protein kinase phosphorylation in muscles. Evid.-Based Complement. Altern. Med. 2016, 2016. [CrossRef] [PubMed]

31. Lin, C.H.; Kuo, Y.H.; Shih, C.C. Eburicoic acid, a triterpenoid compound from Antrodia camphorata, displays antidiabetic and antihyperlipidemic effects in palmitate-treated $\mathrm{C} 2 \mathrm{C} 12$ myotubes and in high-fat diet-fed mice. Int. J. Mol. Sci. 2017, 18, 2314. [CrossRef] [PubMed]

32. Hwang, T.S.; Chan, M.H.; Tsai, W.C. Inhibitory effect on intestinal $\alpha$-glucosidase by extracts of antrodia cinnamomea mycelia and cultural filtrate concentrate. Taiwanese J. Agri. Chem. Food Sci. 2015, 53, 171-176.

33. Du, Y.C.; Wu, T.Y.; Chang, F.R.; Lin, W.Y.; Hsu, Y.M.; Cheng, F.T.; Lu, C.Y.; Yen, M.H.; Tsui, Y.T.; Chen, H.L.; et al. Chemical profiling of the cytotoxic triterpenoid-concentrating fraction and characterization of ergostane stereo-isomer ingredients from Antrodia camphorata. J. Pharm. Biomed. Anal. 2012, 58, 182-192. [CrossRef] [PubMed]

34. Yang, S.W.; Shen, Y.C.; Chen, C.H. Steroids and triterpenoids of Antrodia cinnamomea-A fungus parasitic on Cinnamomum micranthum. Phytochemistry 1996, 41, 1389-1392. [CrossRef]

35. Qiao, X.; Wang, Q.; Ji, S.; Huang, Y.; Liu, K.D.; Zhang, Z.X.; Bo, T.; Tzeng, Y.M.; Guo, D.A.; Ye, M. Metabolites identification and multi-component pharmacokinetics of ergostaneand and lanostane triterpenoids in the anticancer mushroom Antrodia cinnamomea. J. Pharm. Biomed. Anal. 2015, 111, 266-276. [CrossRef] [PubMed]

36. Tai, T.; Akahori, A.; Shingu, T. Triterpenes of Poria cocos. Phytochemistry 1993, 32, 1239-1244. [CrossRef]

37. Lai, C.I.; Chu, Y.L.; Ho, C.T.; Su, Y.C.; Kuo, Y.H.; Sheen, L.Y. Antcin K, an active triterpenoid from the fruiting bodies of basswood cultivated Antrodia cinnamomea, induces mitochondria and endoplasmic reticulum stress-mediated apoptosis in human hepatoma cells. J. Tradit. Complement. Med. 2016, 6, 48-56. [CrossRef] [PubMed]

38. Tien, A.J.; Chien, C.Y.; Chen, Y.H.; Lin, L.C.; Chien, C.T. Fruiting bodies of Antrodia cinnamomea and its active triterpenoid, antcin $\mathrm{K}$, ameliorates $N$-nitrosodiethylamine-induced hepatic inflammation, fibrosis and carcinogenesis in rats. Am. J. Chin. Med. 2017, 45, 173-198. [CrossRef] [PubMed]

39. Lin, T.Y.; Chen, C.Y.; Chien, S.C.; Hsiao, W.W.; Chu, F.H.; Li, W.H.; Lin, C.C.; Shaw, J.F.; Wang, S.Y. Metabolite profiles for Antrodia cinnamomea fruiting bodies harvested at different culture ages and from different wood substrates. J. Agric. Food. Chem. 2011, 59, 7626-7635. [CrossRef] [PubMed]

40. Lin, C.H.; Kuo, Y.H.; Shih, C.C. Antidiabetic and hypolipidemic activities of eburicoic acid, a triterpenoid compound from: Antrodia camphorata, by regulation of Akt phosphorylation, gluconeogenesis, and PPAR $\alpha$ in streptozotocin-induced diabetic mice. RSC Adv. 2018, 8, 20462-20476. [CrossRef]

Sample Availability: Not available.

(C) 2018 by the authors. Licensee MDPI, Basel, Switzerland. This article is an open access article distributed under the terms and conditions of the Creative Commons Attribution (CC BY) license (http://creativecommons.org/licenses/by/4.0/). 